\title{
Commentary
}

\section{First Ruling of the Complaints Committee of the Dutch Agreement on Sustainable Garments and Textile in Response to a Stakeholder Complaint: Arisa vs C\&A Nederland C.V.}

\author{
By Yvonne Erkens, Associate Professor of Labor Law, Leiden University, \\ the Netherlands
}

\section{Introduction}

The Complaints and Disputes Committee (CDC) for the Dutch Agreement on Sustainable Garments and Textile received a complaint document dated 15 May 2020 from the Arisa Foundation (Arisa) and the response document to it dated 12 August 2020 from C\&A Nederland C.V. (C\&A), an apparel and footwear company. On 16 June 2020, the CDC declared Arisa provisionally admissible in its complaint as an interested party. A hearing at which both parties appeared was held on 21 September 2020.

Arisa asserted that employees' rights at an Indian supplier of C\&A have been disregarded and violated. In its complaint document, it specified various malpractices. Arisa expected C\&A, both at this supplier and throughout its entire supply chain, to take responsibility and to draw structural attention to shortcomings and violations of employees' rights. In view of the growing number of violations in the past year, it expected the action to be immediate. More generally, Arisa asserted that C\&A was not willing to share germane information with it. ${ }^{1} \mathrm{C} \& \mathrm{~A}$ asserted that it takes its responsibility very seriously.

1 Complaints and Disputes Committee for the Dutch Agreement on Sustainable Garments and Textile: Arisa vs C\&A Nederland C.V., 9 December 2020, 3.1 and 3.2. 
International responsible business conduct has been a structural component of its policy for more than ten years. It focuses on long-term partnerships and has its own Code of Conduct for the Supply of Merchandise (CoC), which clearly indicates what it expects of suppliers. The $\mathrm{CoC}$ is integral to every business relationship. $\mathrm{C} \& \mathrm{~A}$ monitors and sanctions violations of the $\mathrm{CoC} .{ }^{2} \mathrm{C} \& \mathrm{~A}$ asserted that it is glad to cooperate with external stakeholders, including NGO $\mathrm{s}$ such as Arisa. It strives for continuous improvement of conditions and sustainability throughout the chain. ${ }^{3} \mathrm{C} \& \mathrm{~A}$ responded in regard to each instance of alleged malpractice. ${ }^{4}$

The CDC found the complaint admissible insofar as it was submitted by Arisa as an interested party, that is, the requirements of the CDC Rules of Procedure (Sections 9 and 10) were met. ${ }^{5}$ The CDC declared the complaint that C\&A did not share germane information with Arisa, in particular the remediation plans (specific social information relating to supplier's production site), to be well founded. It declared the other complaints unfounded. ${ }^{6}$

\section{Analysis}

Arisa is a foundation whose mission is to support and strengthen the defense of human rights in South Asia, together with local organizations from the Netherlands. It is a party to the Dutch Agreement on Sustainable Garments and Textile (AGT). C\&A is a signatory to the "Declaration by Enterprises Concerning the Agreement on Sustainable Garments and Textile" and uses Cotton Blossom Private Ltd. in Tamil Nadu, Southern India, to produce garments (Supplier). Arisa voiced several complaints. Two are not discussed here because they were outdated by the time the complaint was processed

First, Arisa asserted that C\&A both did not wish to share germane information with it and did not involve Arisa in any meaningful way. ${ }^{7}$ According to the CDC, the agreement stipulates that a commercial entity that is a party to the AGT, such as C\&A, must basically share any information it has relating to the issue raised with noncommercial entities (other than the State) that are parties to the AGT unless obstacles make it impossible or unreasonable to do so. Such information should not provided only under the pressure

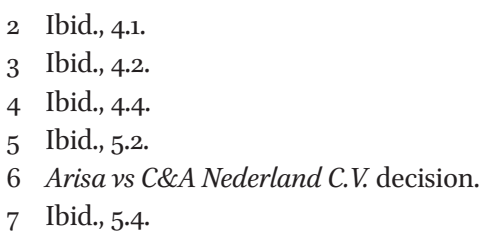


of proceedings. If third-party information is involved, the affiliated entity is expected to make reasonable efforts to obtain that information. ${ }^{8}$ The CDC therefore declared that the complaint that C\&A did not share enough information with Arisa to be well founded.

All other complaints were declared unfounded because Arisa failed to substantiate them adequately. This raises the question of the extent to which a complainant is expected to provide evidence when lodging a complaint. The CDC found that the complaining party, in this case Arisa, must substantiate its complaints in such a way that the other party can properly defend itself against them and that the CDC can render a specific related ruling. The CDC cannot render a decision on complaints or malpractices that are formulated too generally. ${ }^{9}$

One of the latter complaints involved a (female) employee of Supplier who died. After an investigation, C\&A found that the employee had received medical care from the doctor working at the production unit. C\&A had not received any indication that employees were being deprived of adequate medical care or that Supplier had been remiss in any other way. However regrettable this death might have been, in the opinion of the CDC the complaint was not adequately substantiated and was therefore unfounded..$^{10}$ Arisa also asserted that Supplier did too little to prevent dengue. Dengue, an illness transmitted by mosquitoes, occurs in the Tamil Nadu region. The CDC found that the complaint was not adequately substantiated and was therefore unfounded. Furthermore, the spread of dengue as such is not a circumstance within Supplier's control.1

Many of the employees at Supplier's production site lived in hostels. Arisa asserted that the sanitary facilities in some hostels were unhygienic. In the opinion of the CDC, whether Supplier (and by extension, in the context of due diligence, C\&A) was responsible for the quality of the accommodation depended on the extent to which employees saw to their accommodation themselves and the extent to which Supplier was involved. Arisa did not substantiate how Supplier was involved in the accommodation of the (male) employees but did not dispute that Supplier did not own the hostels in question. The CDC also held that it has not been adequately substantiated how C\&A, in view of its twelve obligations pursuant to the agreement, was remiss in this regard. The complaint was therefore unfounded. ${ }^{12}$

\footnotetext{
8 Ibid., 5.5-5.7.

9 Ibid., 5.11-5.15.

10 Ibid., 5.18-5.20.

$11 \quad$ Ibid., 5.21.

12 Ibid., $5.22-5.23$.
} 
Arisa also complained that Supplier worked with contract employees and pieceworkers and that this increased the risk of illegal labor and exploitation, as is evidenced by a report that Arisa submitted demonstrating that this is common in the garment industry in India. C\&A stated that to the best of its knowledge Supplier did not work with contract employees or pieceworkers, and that, furthermore, these types of contract are permitted in India. In the CDC's opinion, Arisa has not made this complaint specific enough, instead merely referring to the general report it submitted..$^{13}$

Finally, Arisa complained about the complaint mechanism at the supplier level. According to OECD guidelines, a company must have a functioning internal complaint mechanism. Indian legislation requires an enterprise to set up various committees in this context, including a Works Committee. Arisa indicated that Supplier had established the legally required Works Committee, but that it received no complaints. Arisa pointed out that this circumstance indicates a nonfunctioning internal complaint mechanism that poses a risk to the welfare of employees. C\&A stated that it had asked Supplier about the situation. Supplier responded that it complied with the legal requirements and that various complaint mechanisms were in place, including a complaints box and a monthly meeting with employees. According to the $\mathrm{CDC}$, that no complaints were received by the Works Committee could have been an indication to C\&A of the inadequate or poor functioning of the complaint mechanism at Supplier and accordingly could have been a reason to take action. In view of this, the CDC recommended to C\&A (without this being binding) that in situations when malpractices are clear but no complaints have been made within the complaint mechanism, C\&A should enter into discussions with the owners or operators of the production site to determine how they could improve the functioning of the complaint mechanism, for example by looking at the criteria set out in United Nations Guiding Principle on Business Human Rights No. $31 .^{14}$

\section{Conclusions}

From a procedural perspective, the first notable factor is that the committee receives anonymous complaints only under strict conditions. In this procedure, Arisa acted also on behalf of a local organization and local employees, who remained anonymous. Because the issuer of the mandate to Arisa was

\footnotetext{
13 Ibid., 5.27.

14 Ibid., $5 \cdot 30-5 \cdot 34$.
} 
unclear, the complaint was inadmissible. The CDC expects a complainant to look for ways to achieve a degree of confidentiality when reason exists to do so. Arisa could have requested the CDC to provide the mandate and the names of the local organization or local employees only to the CDC and not to C\&A when keeping those names confidential was justifiable. ${ }^{15}$

The company's duty to provide information is also clarified in this ruling. The starting point is the sharing of information without the company's harming itself or others by doing so. The company must make a good faith effort to obtain information from third parties.

Where obligations in the supply chain are concerned, the CDC stressed that the basic principle when assessing a complaint is the action taken by the party to the agreement, in this case C\&A, in the light of the agreement, not the actions or omissions of the owner or operator of the production site or those of the local authorities involved. The point is whether the other party has failed to fulfill its obligations pursuant to the agreement. ${ }^{16}$

Finally, an important lesson involves the indirect gains from a proceeding such as this. Of all the complaints, only one was founded, but Arisa did have a forum in which the others were seriously examined. The ruling states in so many words that " $\mathrm{C} \& \mathrm{~A}$ has adopted a cooperative stance in the proceedings." This is important not only for this procedure but also for future situations in which C\&A, when again called to account for its obligations under the Agreement on Sustainable Garments and Textile, may be more inclined to enter into dialogue, and thus reach solutions more quickly.

15 Ibid., 5.3.

16 Ibid., 5.11-5.15. 